\title{
Identifying factors affecting acceptance of new technology in the industry using hybrid model of UTAUT and FUZZY DEMATEL
}

\author{
Mojtaba Javidnia ${ }^{a^{*}}$, Somaye Nasiri ${ }^{b}$ and Jamshid kiani far ${ }^{c}$
}

\begin{abstract}
${ }^{a}$ Department Of Management, Young Researchers Club, Semnan Branch, Islamic Azad University, Semnan , Iran ${ }^{b}$ Department Of Management, Semnan Branch, Islamic Azad University, Semnan , Iran ${ }^{c}$ PHD of management business- Expert research and entrepreneurship, Payam noor University, garmsar, Iran

\begin{tabular}{|c|c|}
\hline A R T I C L E I N F O & A B S T R A C T \\
\hline $\begin{array}{l}\text { Article history: } \\
\text { Received March 29, } 2012 \\
\text { Received in Revised form } \\
\text { June, } 18,2012 \\
\text { Accepted } 20 \text { July } 2012 \\
\text { Available online } \\
\text { August } 12012 \\
\text { Keywords: } \\
\text { Unified Theory of Acceptance and } \\
\text { Use of Technology } \\
\text { FUZZY DEMATEL(UTAUT) } \\
\text { Electro-Slag Remelting (ESR) }\end{array}$ & $\begin{array}{l}\text { Today and in highly competitive and fast-paced arena of the world, industrial companies focus } \\
\text { on achieving technological superiority through the effective use of world modern-day } \\
\text { technologies in the production and operation process associated with all their available } \\
\text { resources. With using this procedure, these industrial companies try to achieve long-term and } \\
\text { sustainable competitive advantages. On the other hand, applying world modern technologies } \\
\text { does not solely guarantee success of these companies, rather, preparing preliminary grounds } \\
\text { associated with the acceptance of technology will be decisive in this field. This article deals } \\
\text { with clarifying factors affecting the adoption of new technologies and showing relationship of } \\
\text { these factors together. For this purpose, Unified Theory of Acceptance and Use of Technology } \\
\text { (UTAUT) Model has been used to study factors affecting the adoption of new technologies. In } \\
\text { the same direction, relationship between constituent components of this model has been studied } \\
\text { with regard to the acceptance of new technology of Electro-Slag Remelting (ESR) in Esfarayen } \\
\text { Steel Industry Complex using FUZZY DEMATEL Technique. }\end{array}$ \\
\hline
\end{tabular}
\end{abstract}

(c) 2012 Growing Science Ltd. All rights reserved.

\section{Introduction}

Over the past 20 years, acceptance of technology has been considered as one of the most important issues in organizations (Pontiggia \& Virili, 2010) and many models have been developed and created in order to describe and to analyze the factors affecting acceptance and application of new technology (Kijsanayotina et al., 2009). Fishbein and Ajzen (1975) proposed Theory of Reasoned Action (TRA). This Theory explains person's behavioral tendencies with the aim of predicting changes and interpreting particular personal behavior clearly and emphasizes on this subject that individuals' behavior is shaped by their behavioral intentions, based on which, the very behavioral intentions depend on personal attitudes and subjective norms. Ajzen (1985) proposed Theory of Planned 
Behavior (TPB), which was an extension of TRA in an attempt to provide a better prediction and interpretation. There are some differences between TPB and TRA: In TRA, behaviors and events are less controllable while in TPB, behavior is based on the assumptions that all behaviors are more controlled (Pai \& Huang, 2011). A few years later, Davis et al. (1989) presented Technology Acceptance Model (TAM) to explain relationship between perceived emotions factor and application of science and technology. TAM shows the way of behavior of users in acceptance and use of new technology (Kwon \& Wen, 2010).

As a reliable tool, this model has been approved noticeably by interns of technology management field to predict new technologies. The figure of this model has been based on two factors of Perceived Usefulness (U) and Perceived Ease of Use (E), in which, these two factors determine behavioral tendency of individuals to the use of new technology (Greenfield \& Rohde, 2009). This model was soon used as one of the most common and important conceptual models associated with the acceptance of technology in different environments and systems across the world (Al-Ghahtani, 2011). To date, several experimental studies have been carried out based on TAM and with the centrality of analyzing subjects and variables related to the acceptance of technology (Pontiggia \& Virili, 2010). Since establishment of TAM, some researchers were after improving and correcting it to increase capability of description and explanation of TAM Model (Lee et al., 2010). Theoretical extension of Technology Acceptance Model (TAM2) was one of the models, which were proposed to improve main model.

By considering factors of social influences (subjective norm, voluntariness and subjective image) and also perceived usefulness (U) factors (job relevance, output quality and result demonstrability) it is possible to consider more effective application of TAM (Yua et al., 2009). Finally, more developed model than the TAM and TAM2 models named "UTAUT", was provided by Venkatesh et al. (2003). This model suggests that acceptance and application of new technologies by users is mainly affected by four factors: Performance Expectancy (PE), Effort Expectancy (EE), Social Influence (SI) and Facilitating Conditions (FC). They reviewed the main characteristics of models of acceptance of technology and analyzed existing relationship between factors affecting the acceptance of technology using UTAUT Model.

FUZZY DEMATEL Technique was used to simplify complex relationship network of these factors. While showing effect of each factor on all network components, this technique determines the factors, which play an important role in whole network in order to provide a preliminary ground for drawing attention of managers to them. It is obvious that more attention of managers to key factors of acceptance of new technologies by users facilitates the possibility of implementation and effective application of these technologies and improves conditions of success in technology transfer projects.

\section{Technology acceptance models}

\subsection{TAM Model}

This model shown in Fig. 1 deals with analyzing effects of external factors on beliefs, approaches, attitudes and tendency of individuals (Jan \& Contreras, 2011). As mentioned earlier, TAM explains that the Perceived Usefulness (U) and Perceived Ease of Use (E) are considered as two key factors in determination of the way of acceptance of a technology by users (Teo, 2011). The Perceived Usefulness (U) means the degree a person feels that application of a technology promotes his/her job performance (Davis et al. 1989). In addition, Perceived Ease of Use (E) refers to the imagination of user on ease of using the new technology. Learning the system easier follows their more positive attitude to use it. Both perceived usefulness and perceived ease of use are influenced by the external variables.

The external variables include technological characteristics, education, and training, participation of user in system design and nature of system processes. All external variables affect users' behavioral 
intentions and use of system directly (Lee et al., 2011). If user feels that new technology is appropriate for his/her job performance, he/she will show positive feeling to use it and will have better attitude to use the new technology. Also, attitudes affect behavioral intentions of users and actual system use (Pai \& Huang ., 2011). The aim of TAM Model is to meet this expectation that this model can be used as a standard model for distributing or predicting application of technology (Lee et al., 2011).This model is used vastly in studies and in order to analyze and predict regarding acceptation of technology in various industries (Lee et al., 2010).

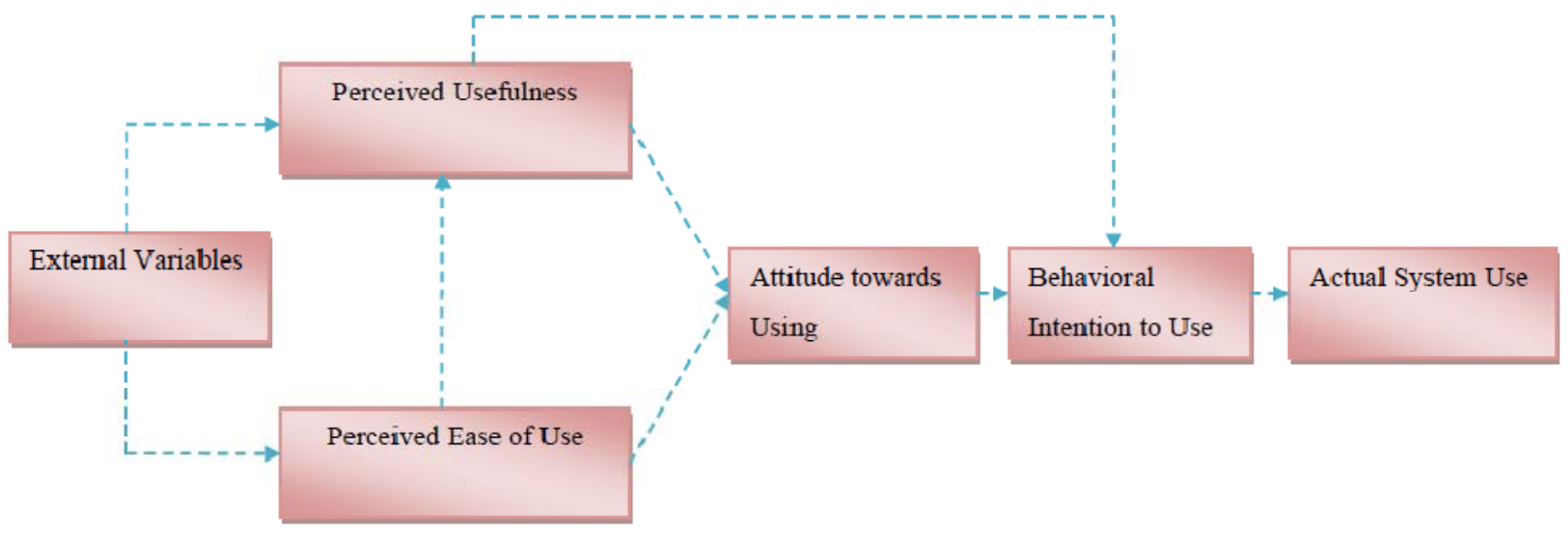

Fig.1. TAM model

\subsection{TAM2 Model}

Theoretical Extension of Technology Acceptance Model or TAM2 is one of other theoretical frameworks, which increase perception of managers to the reaction of users in order to accept technology. This model, as shown in Fig. 2 is a developed version of the main model of acceptance of technology, which has been created in order to describe perceived usefulness and practical purposes with considering social influences and subjective structural processes. TAM2 is distinctive by adding three variables from Tam's Model. These three variables include subjective norm, voluntariness and mental image (Soroa et al., 2010). Based on the definition proposed by Venkatesh and Davis (2000), subjective norm is known as an individual perception that more people concentrate on it and carry out a specific behavior according to it. Therefore, Venkatesh and Davis (2000) emphasized on this point that subjective norm is a direct determinant factor in willingness to use. In addition, voluntary variable refers to the degree that user perceives that acceptance of technology is not compulsory and finally, subjective image refers to the subjectivity of a person on the point that application of an innovation or new technology promotes his status and position in his social system.

Generally speaking, it can be said that this model includes subjective norms, image, voluntariness and experience. Moreover, this model is a perceived structural process including job relevance, output quality and result demonstrability. In TAM2 model, subjective norm affects directly to the perceived usefulness and indirectly to the appetite for use. In addition, subjective norm affects the perceived usefulness indirectly and subjective norm can affect directly on appetite for change (Lee et al., 2010).

The researches show that subjective norms may affect more on involuntary environment. On the other hand, subjective norm is affected on the behavioral tendency by the voluntariness of user. While using a system, behavioral intentions change with regard to the willingness. In addition, subjective norm is influenced by the experience. When users are unfamiliar with a system relatively, subjective norm affects on their use from that system clearly (Lee et al, 2011). TAM2 Model expanded social influence factor and analyzed two main influential processes (social influence process and perceived structural process) deeply and completely in formation of perceived usefulness of technology. Therefore, TAM2 has more ability of interpreting and describing than TAM Model (Yua et al., 2009). 


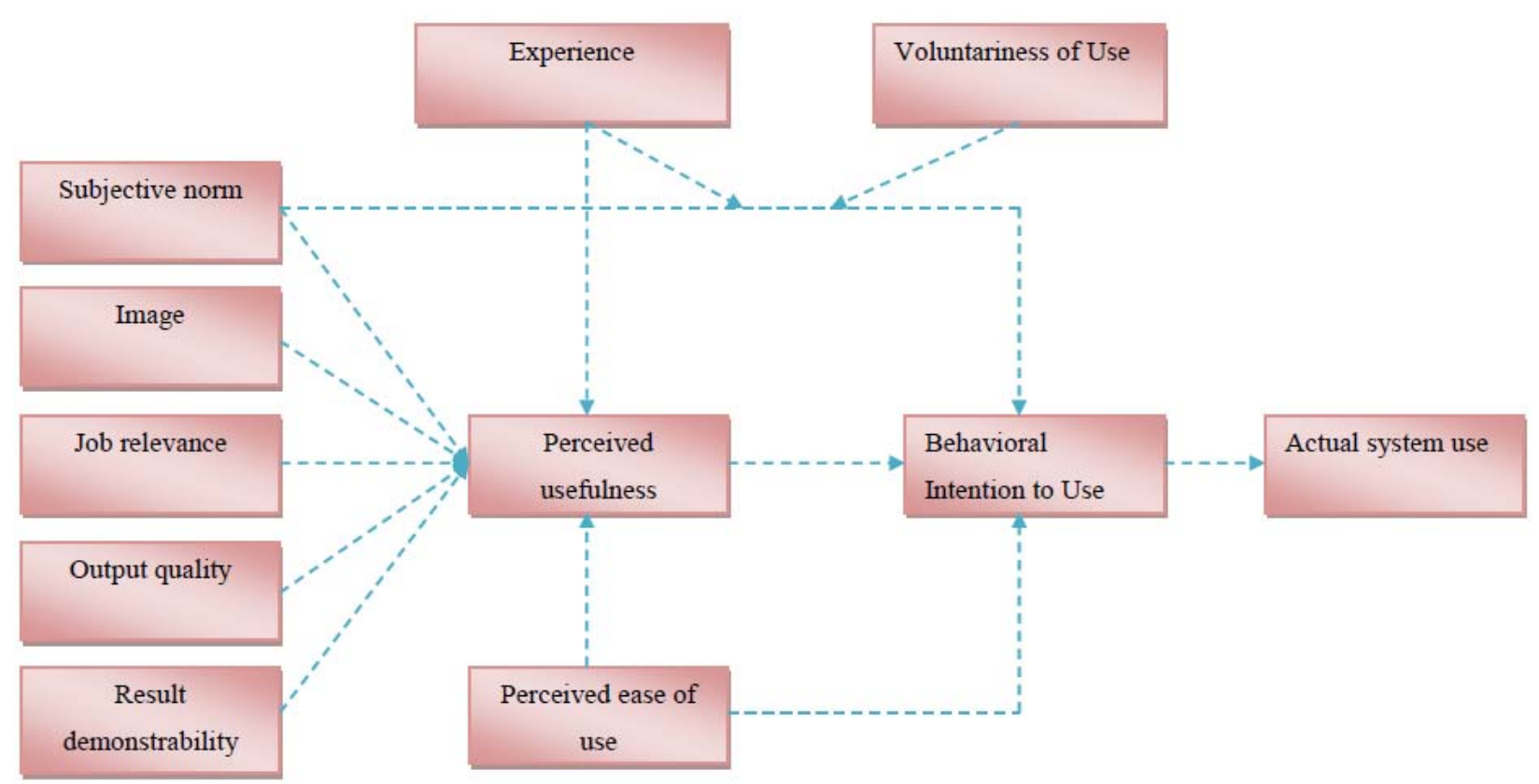

Fig. 2.TAM2 model

\subsection{UTAUT (Unified Theory of Acceptance and Use of Technology) Model}

Venkatesh et al. (2003) compared and studied available variables in eight different models of acceptance of technology and proposed UTAUT, which includes four main variables (Performance Expectancy (PE), Effort Expectancy (EE), Social Influence (SI) and Facilitating conditions (FC) (Venkatesh et al., 2003). Since UTAUT Model has been created from integration of eight important theories and has been tested on a complex of actual world data, it is used as a significant model (Im et al., 2011). These eight theories include Theory of Reasoned Action (TRA), Technology Acceptance Model (TAM), Theory of Planned Behavior (TPB), Motivation Model, combination of Technology Acceptance Model (TAM) and Theory of Planned Behavior (TPB), Model of Applying Personal Computers, Theory of Expansion of Innovation and Theory of Social Cognition for describing phenomena in various fields. Venkatesh et al. (2003) merged these models together and showed efficiency of their proposed model by the empirical researches.

UTAUT Model has summarized the factors, which have been recognized effective on behavioral intentions and users' actual use in these eight models, in four determinant factors: 1- Performance Expectancy: Is a degree that a person believes that using a system will help him greatly achieve more success in his work performance. Therefore, Performance Expectancy (PE) affects positively on the behavioral intentions. 2. Effort Expectancy (EE) is a degree that a person believes that using technology will lead to less individual effort. 3. Social Influence (SI): Users are always affected by viewpoints and attitudes of others in the field of acceptance of technology. 4. Facilitating Conditions (FC) is a degree or the rate, where a person believes that there is a necessary technical and organizational infrastructure to support use of a technology or system. These four determinant factors are influenced by adjustment variables of gender, age, experience and voluntariness of use of technology and consequently, different levels of changes are created for behavioral tendencies (Teo, 2011). Generally, UTAUT Model concentrates on the causal (cause and effect) relationship between individual attitudes towards using a technology, personal tendencies towards using a technology, actual use of a technology and identifying performance expectancy of a technology. In this model, Facilitating Conditions (FC) is introduced as a main determinant factor in the use of a technology or system (Liu \& Forsythe, 2011).This model has been shown in Fig. 3. 


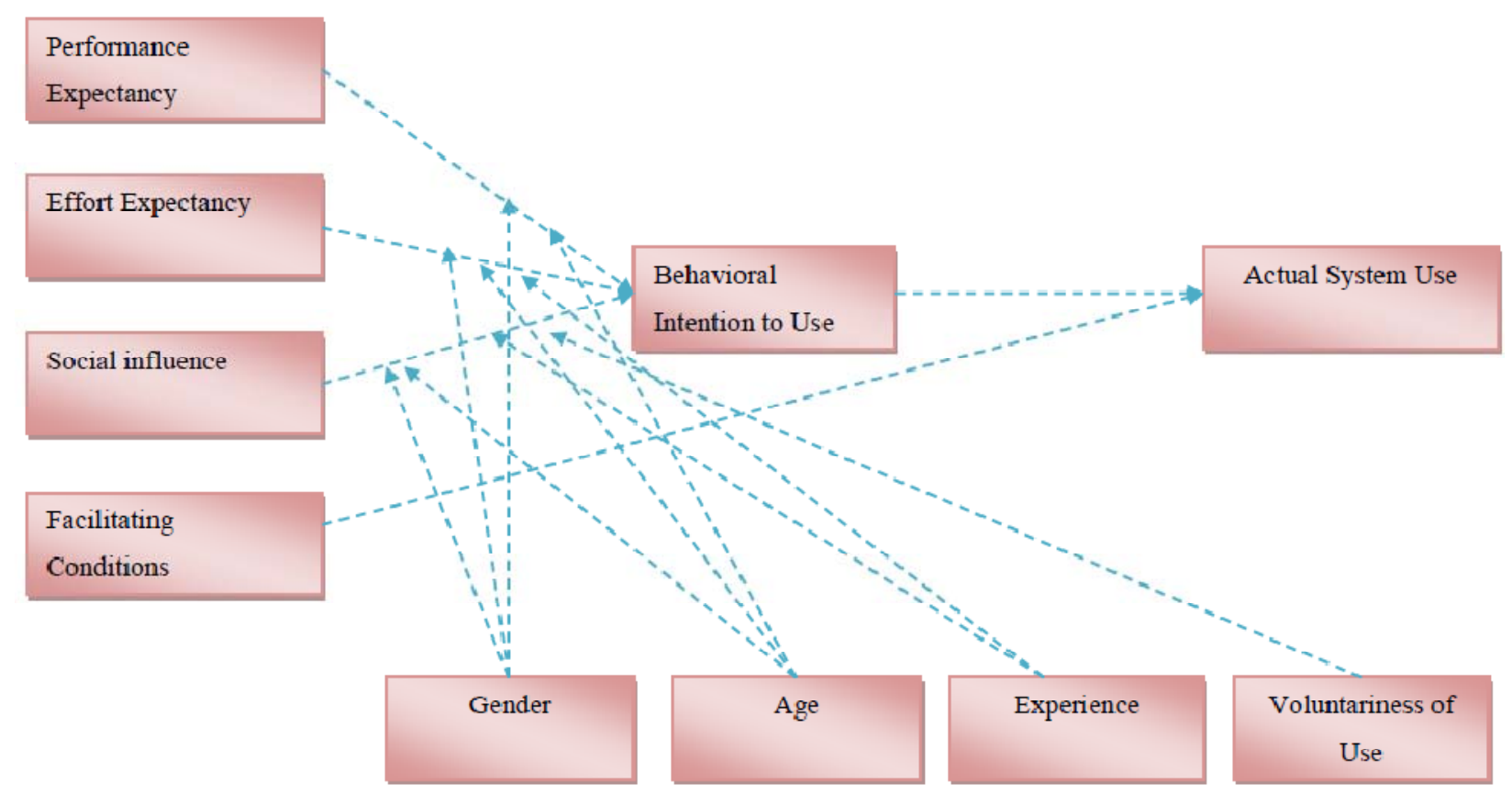

Fig. 3. UTAUT model

\subsection{DEMATEL}

DEMATEL was first introduced at Battelle Memorial Institute of Geneva Research Center. This method was applied in relation to complicated problems of the world such as famine, energy, environmental protection and etc in that time (Fontela \& Gabus, 1976). DEMATEL is one the multi criteria decision making instruments and has the ability to convert the qualitative designs to the quantitative analysis (Lee et al., 2011). The aim of DEMATEL is to convert the relation between criterions, causal dimensions from a complex system to an understandable structural model of that system (Dalalah et al., 2011). All criteria of a system, directly or indirectly, are mutually related to each other in a general reciprocal system. So each change in one of criteria will influence on other criteria (Tzeng et al., 2007). This technique is successfully applied in other circumstances such as development methods, management systems, electronic learning evaluation, knowledge management, etc. (Kuoa \& Liang, 2011). Japan, Korea and Taiwan have widely used DEMATEL technique for successful solving of different problems in different fields (Lin \& Wu, 2008).

\subsection{Fuzzy-logic}

Many of the organizations accepted group decisions in order to find a solution. Group decision means to achieve an agreement through dialogue many experts and in this case, an acceptable decision can be adopted. Of course, in the decision related to complex systems, assessment by experts or decisionmakers about a qualitative criteria object will be presented, always couched in language (and not in the form of determined quantities) and based on experience and skill of them. Since the theory of fuzzy collection can be used to measure ambiguous concepts based on unreal (personal) judgments. Based on Table 1, we can change the vague judge to fuzzy triangle numbers.

\section{Table1}

The correspondence of linguistic terms and values

\begin{tabular}{lc}
\hline Linguistic values & Linguistic terms \\
\hline$[0.75,1,1]$ & Very high influence(VH) \\
{$[0.5,0.75,1]$} & High influence(H) \\
{$[0.25,0.5,0.75]$} & Low influence (L) \\
{$[0,0.25,0.5]$} & Very low influence (VL) \\
{$[0,0,0.25]$} & No influence (NO) \\
\hline
\end{tabular}


Fuzzy triangle Number can be a regular triplets $(\mathrm{l}, \mathrm{m}, \mathrm{n})$ that showed $1 \leq \mathrm{m} \leq \mathrm{n}$. For both fuzzy Triangle numbers $A_{1}=\left\{l_{1}, m_{1}, r_{1}\right\} A_{1}=\left\{l_{2}, m_{2}, r_{2}\right\}$, regular arithmetic operations are performed as follows,

$$
A_{1}+A_{2}=\left(l_{1}+l_{2}, m_{1}+m_{2}, r_{1}+r_{2}\right) \quad A_{1}-A_{2}=\left(l_{1}-l_{2}, m_{1}-m_{2}, r_{1}-r_{2}\right) \quad A_{1} \otimes A_{2}=\left(l_{1} l_{2}, m_{1} m_{2}, r_{1} r_{2}\right) \quad \lambda A_{1}=\left(\lambda l_{1}, \lambda m_{1}, \lambda r_{1}\right),(\lambda>0)
$$

Since fuzzy numbers are not suitable for Matrix operation, defuzzy algorithm is needed. Defuzzy is a method to change fuzzy numbers to real numbers. In recent years, different types of defuzzy methods have been introduced. However, in practice, to choose the best method we need all types of qualities and characteristics such as shape, scope, height, and place phase (Opricovic \& Tzeng, 2003). In the meantime, the especial unknown and instable environment where fuzzy numbers are used should be considered by selecting the method of defuzzy. At present, the process of defuzzy, santroid, (the center of gravity) proposed by Yager and Philo (1994) is used (Kanter, 1985). But this method is not able to differentiate the two fizzy numbers with different forms which are changed to a determined numbers, using this method (Kouriloff, 2000), so this study used CFCS ( changing the fuzzy data into determined values) proposed by Opricovic and Tezeng (2003) to defuzzy numbers. According to process of CFCS method, at first, right and left values would be determined with a minimum and maximum fuzzy based on the fuzzy numbers based in the group evaluating and then the final definite number would be calculated in the form of average weight based on membership subject.

\subsection{The Fuzzy DEMATEL`s steps}

1.We specify evaluation factors according to expert committee’s opinion and research background.

2.We determine each factor influences on whole system, according to expert's opinion. To do so, we use discussed wordy expressions in Table 2 and Fig. 4. Then, we used CFC method Eqs. (1-9) to convert the fuzzy numbers into crisp values.

\section{Table2}

The correspondence of linguistic terms and values

\begin{tabular}{lc}
\hline Linguistic values & Linguistic terms \\
\hline$[0.75,1,1]$ & Very high influence(VH) \\
{$[0.5,0.75,1]$} & High influence(H) \\
{$[0.25,0.5,0.75]$} & Low influence (L) \\
{$[0,0.25,0.5]$} & Very low influence (VL) \\
{$[0,0,0.25]$} & No influence (NO) \\
\hline
\end{tabular}

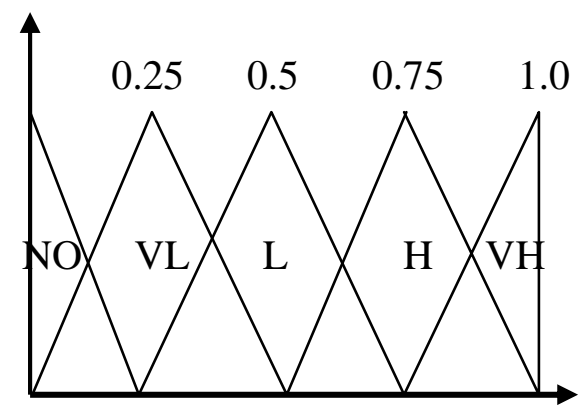

Fig. 4. Fuzzy triangle numbers

$$
\begin{aligned}
& X L_{i j}^{k}=\left(L_{i j}^{k}-\min _{i j}^{k} L_{k \leq k}^{k}\right) / \Delta_{\min }^{\max } \\
& X M_{i j}^{k}=\left(M_{i j}^{k}-\min _{i j}^{k} L_{1 \leq k}^{k}\right) / \Delta_{\min }^{\max }
\end{aligned}
$$


$X r_{i j}^{k}=\left(r_{i j}^{k}-\operatorname{minL}_{1 \leq k \leq k}^{k}\right) / \Delta_{\min }^{\max }$

$\Delta_{\min }^{\max }=\max r_{i j}^{k}-\min L_{i j}^{k}$

$X l s_{i j}^{k}=\frac{X m_{i j}^{k}}{\left(1+X m_{i j}^{k}-X l_{i j}^{k}\right)}$

$X r s_{i j}^{k}=\frac{X r_{i j}^{k}}{1+X r_{i j}^{k}-X m_{i j}^{k}}$

$X_{i j}^{k}=\left[X l s_{i j}^{k}\left(1-X l s_{i j}^{k}\right)+X r s_{i j}^{k} \cdot X r s_{i j}^{k}\right] /\left(1+X r s_{i j}^{k}-X l s_{i j}^{k}\right)$

$B N P_{i j}^{k}=\min L_{i j}^{k}+X_{i j}^{k} \Delta_{\min }^{\max }$

$a_{i j}=\frac{1}{k} \sum_{k}^{1 \leq k \leq k} B N P_{i j}^{k}$

$\mathrm{A}=\left[\mathrm{a}_{\mathrm{ij}}\right]$ is direct relations matrix of experts opinions.

3. Obtaining total relations matrix T- I is identity matrix $n \times n$ and $T=\left[t_{i j}\right]$ elements indicate the direct and indirect influences of factor $i$ on factor $j$. So matrix $T$ can be indicator of general relations between each pair factor in the system. Matrix $D$ is the normalized matrix. $D=\left[d_{i j}\right], 0 \leq d_{i j} \leq 1$.

$$
\begin{aligned}
D & =\frac{1}{\max _{1 \leq i \leq n} \sum_{j=1}^{n} a_{i j}} A \\
T & =D(I-D)^{-1}
\end{aligned}
$$

4. Calculation of row summation and column summation of $T$ matrix - i row summation is indicator of all direct and indirect influences of $i$ factor on all other factors and so can call $r_{i}$ as the influencing degree. $C_{j}$ is similarly, the column summation and we can call it as influenced degree of $j$ factor.

$\begin{aligned} r_{i} & =\sum_{1 \leq i \leq n} t_{i j} \\ C_{j} & =\sum_{1 \leq i \leq n} t_{i j}\end{aligned}$

Therefore, when $i=j, r_{i}+c_{i}$ shows both the influence which $i$ factor can have on other factors of system and also the influences of other factors of system on $i$ factor. So, $r_{i}+c_{i}$ show the significant degree of $i$ factor in whole system, and $r_{i}-c_{i}$ indeed shows the influence of $\mathrm{i}$ on system. If $r_{i}-c_{i}$ is positive, $i$ factor belong to the cause group and if $r_{i}-c_{i}$ is negative, $i$ factor belong to the effect group.

5. Finally, We show the diagram of factors influencing on $r_{i}-c_{i}$ and $r_{i}+c_{i}$ bases. This diagram is drawn by $\left(r_{i}+c_{i}, r_{i}-c_{i}\right)$ coordinate (Huang, 2009). 


\section{A Brief Review of Research}

Technology acceptance has thus far been used in different studies and in various fields. Some studies have emphasized on the process of acceptance of technology while some others have concentrated on the relationship between acceptance of technology and technologies affecting it, based on which, UTAUT Model belongs to this Group. Some of the researches carried out in the field of UTAUT Model. Im et al. (2010) investigated the relationships of the constructs in the UTAUT framework to determine how they are influenced by culture by collecting the necessary data from Korea and the U.S. They examined two technologies including the MP3 player and Internet banking. Their results indicated that the UTAUT model fits their data well. The comparison of Korea and the U.S. also disclosed that the effects of effort expectancy on behavioral intention and the impacts of behavioral intention on use behavior were bigger in the U.S. sample. Liu and Forsythe (2011) examined whether the early adopters of the online channel were more likely to purchase wide range of products and more frequently than others based on UTAUT model. They examined the direct effects of perceived usefulness, enjoyment, product risk, and internet usage at home and at work on post-adoption buy intensity using a structural equation modeling approach. In addition, they investigated the moderating effects of adoption duration to compare hypothesized relationships across groups of early and late adopters. They reported that factor effects on predicting purchase intensity were different across the groups of early and late adopters. Zhou et al. (2010) proposed a mobile banking user adoption model and based on UTAUT model reported that performance expectancy, task technology fit, social influence, and facilitating conditions had important impacts on user adoption. Goktalaya and Ozdileka (2010) investigated the pre-service teachers' perceptions about Web 2.0 technologies in their learning process and their acceptance levels and attitudes towards these tools. The survey was built on three components including demographic data, Web 2.0 attitude scale, and UTAUT scale. The results showed that participants' perceptions about Web 2.0 technologies were positive and acceptance and willingness to use these technologies was high. Lee et al. (2010) adopted the view point of the UTAUT model to investigate the change agents' behavioral intentions in the implementation of an activity based costing/management (ABC/M) system. Kijsanayotina et al. (2009) employed a UTAUT structural model to understand factors that impact health IT adoption in community health centers in Thailand and to validate this extant IT adoption model in a developing country health care context.

\section{Methodology}

In this article, FUZZY DEMATEL Technique has been used in order to study causal relationship between components of UTAUT Model. Key success factors were identified through using this method.

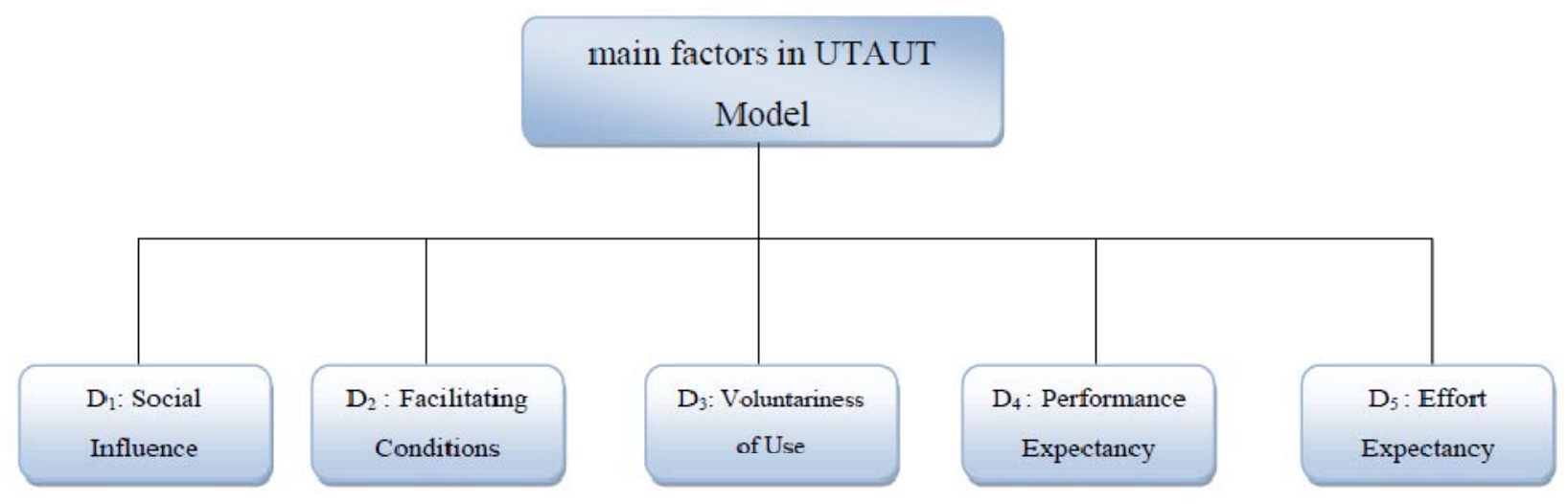

Fig.5. main factors in UTAUT Model

While entering new technology and adapting it with its internal processes, this technique empowered organization to focus on them. So, organization can make its application more effective through 
appropriate use of new technology. Viewpoints of experts, who enjoyed specialty and experience in transfer of similar technologies, were used to achieve this objective and finally, five main factors were identified in UTAUT Model. These factors have been displayed in the Fig. 5. Eqs (1-9) were obtained through matrix of direct relationship after de-fuzzy stages and merging comments of six experts. It should be noted that experts used verbal statements (Table 2) in filling out questionnaire. Matrix of direct relations (A) in Table 4 and General relations matrix (T) in Table 5 are shown.

Table 4

Direct relations matrix (A)

\begin{tabular}{cccccc}
\hline $\begin{array}{c}\text { Factor } \\
\mathrm{s}\end{array}$ & $\mathrm{D}_{1}$ & $\mathrm{D}_{2}$ & $\mathrm{D}_{3}$ & $\mathrm{D}_{4}$ & $\mathrm{D}_{5}$ \\
\hline $\mathrm{D}_{1}$ & 0 & 0.004 & 0.499 & 0.004 & 0.004 \\
$\mathrm{D}_{2}$ & 0.499 & 0 & 0.625 & 0.004 & 0.004 \\
$\mathrm{D}_{3}$ & 0.499 & 0.888 & 0 & 0.004 & 0.004 \\
$\mathrm{D}_{4}$ & 0.511 & 0.499 & 0.699 & 0 & 0.004 \\
$\mathrm{D}_{5}$ & 0.511 & 0.326 & 0.625 & 0.326 & 0 \\
\hline
\end{tabular}

Table 5

General relations matrix -T Matrix

\begin{tabular}{cccccc}
\hline Factors & $\mathrm{D}_{1}$ & $\mathrm{D}_{2}$ & $\mathrm{D}_{3}$ & $\mathrm{D}_{4}$ & $\mathrm{D}_{5}$ \\
& & & & & \\
\hline $\mathrm{D}_{1}$ & 0.171 & 0.204 & 0.402 & 0.005 & 0.004 \\
$\mathrm{D}_{2}$ & 0.539 & 0.308 & 0.612 & 0.007 & 0.006 \\
$\mathrm{D}_{3}$ & 0.598 & 0.710 & 0.420 & 0.007 & 0.006 \\
$\mathrm{D}_{4}$ & 0.721 & 0.702 & 0.843 & 0.006 & 0.007 \\
$\mathrm{D}_{5}$ & 0.774 & 0.673 & 0.876 & 0.189 & 0.006 \\
\hline
\end{tabular}

The total of the given effects and receiving effects of the factors (cause and effect matrix) and the graph of the effect of the factors were respectably shown in Table 6 and Fig. 6.

Table 6

Calculating the influences of each factor

\begin{tabular}{ccccc}
\hline Factors & $\boldsymbol{r}_{\boldsymbol{i}}$ & $\boldsymbol{C}_{\boldsymbol{i}}$ & $\boldsymbol{r}_{\boldsymbol{i}}+\boldsymbol{C}_{\boldsymbol{i}}$ & $\boldsymbol{r}_{\boldsymbol{i}}-\boldsymbol{C}_{\boldsymbol{i}}$ \\
\hline $\mathrm{D}_{1}$ & 0.786 & 2.804 & 3.589 & -2.018 \\
$\mathrm{D}_{2}$ & 1.472 & 2.597 & 4.069 & -1.125 \\
$\mathrm{D}_{3}$ & 1.741 & 3.153 & 4.894 & -1.412 \\
$\mathrm{D}_{4}$ & 2.280 & 0.213 & 2.493 & 2.066 \\
$\mathrm{D}_{5}$ & 2.517 & 0.029 & 2.546 & 2.489 \\
\hline
\end{tabular}

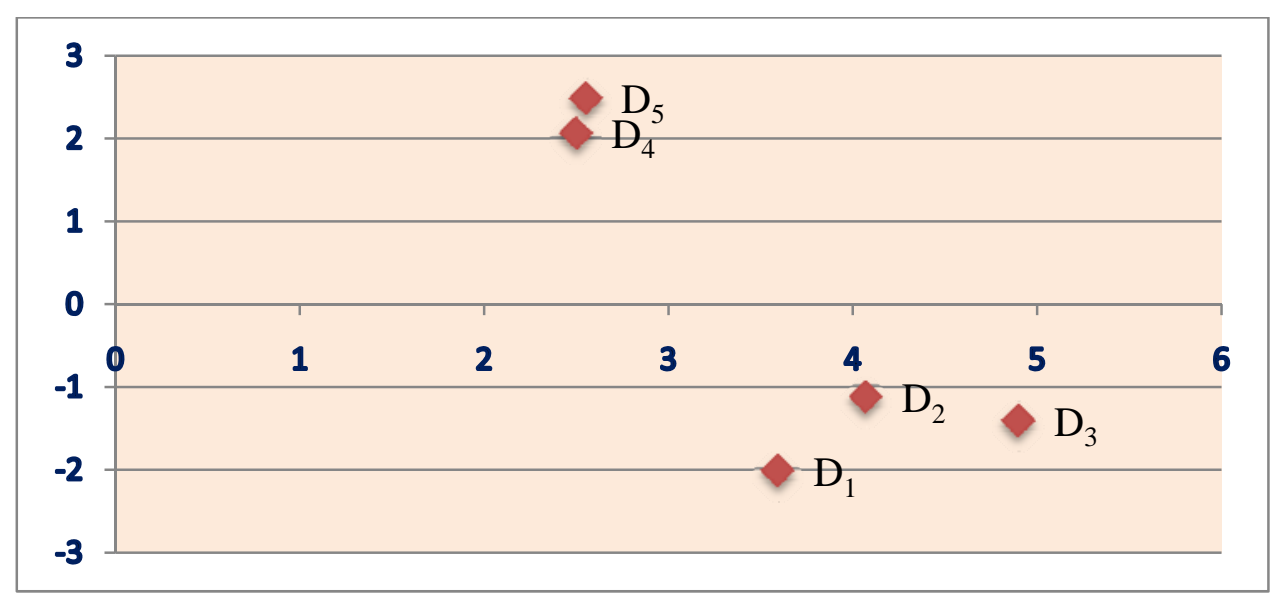

Fig. 6. the casual diagram

\section{Conclusion}

Technology acceptance models are based on the assumption that behavioral intention to use technology is affected by various internal and external factors. In this line and in order to understand and study intention to use and acceptance of technology by users precisely, it is necessary that effects of internal and external factors and relations among all variables, perceptions should be specified clearly. In this article, FUZZY DEMATEL method has been used to achieve the abovementioned objectives and to eliminate existing ambiguities in some judgments. This method removes all problems associated with lack of perception and enough experience of users as well as shortage of statistical subject and enjoys this ability to explain causal relationship between UTAUT model and 
effect of each of these factors on technology acceptance by user, clearly. For this purpose and after fulfilling necessary calculations, diagram of the factors obtained and factors were placed in two groups, the cause group including $\mathrm{D}_{5}$ and $\mathrm{D}_{4}$ and the effect group including $\mathrm{D}_{2}, \mathrm{D}_{3}$ and $\mathrm{D}_{1}$. The factors of cause group are called "key success factors" and managing with concentrating on them can settle facing problems and restrictions with relation to the acceptance of new technologies by the users.

\section{References}

Al-Ghahtani, S.S. (2011). Modeling the electronic transactions acceptance using an extended technology acceptance model. Applied Computing and Informatics, 9, 47-77.

Davis, F.D., Bagozzi, R.P., \& Warshaw, P.R. (1989). User acceptance of computer technology: A comparison of two. Management Science, 35(8), 982-1003.

Goktalaya, S.B., \& Ozdileka, Z. (2010). Pre-service teachers’ perceptions about web 2.0 technologies. Journal of Procedia Social and Behavioral Sciences, 2, 4737- 4741.

Greenfield, G., \& Rohde, F. (2009). Technology acceptance: Not all organisations or workers may be the same. International Journal of Accounting Information Systems, 10, 263-272.

Im, I., Hong, S., \& Kang, M.S. (2011). An international comparison of technology adoption Testing the UTAUT model. Journal of Information \& Management, 48, 1-8.

Jan, A.U., \& Contreras, V. (2011). Technology acceptance model for the use of information technology in universities. Computers in Human Behavior, 27, 845-851.

Kijsanayotina, B., Pannarunothaib, S., \& Speediec, S.M. (2009). Factors influencing health information technology adoption in Thailand's community health centers: Applying the UTAUT model. International journal of medical informatics, 78, $404-416$.

Kwon, O., \& Wen, Y. (2010). An empirical study of the factors affecting social network service use, Comput. Hum. Behav. 26 (2) 254-263.

Lee, C.L., Yen, D.C., Peng, K.C., \& Wu, H.C. (2010). The influence of change agents' behavioral intention on the usage of the activity based costing/management system and firm performance: The perspective of unified theory of acceptance and use of technology. Journal of Advances in Accounting, incorporating Advances in International Accounting, 26, 314 -324.

Lee,Y. C., Lee, M. L., Yen, T. M., \& Huang, T. H. (2010). Analysis of adopting an integrated decision Making Trial and Evaluation Laboratory on a technology acceptance model. Expert System with Applications, 37(1), 1745-1754.

Lee, Y. C., Lee, M. L., Yen, T. M., \& Huang, T. H. (2011). Analysis of fuzzy Decision Making Trial and Evaluation Laboratory on technology acceptance model. Expert Systems with Applications, 1-10.

Liu, C., \& Forsythe, S. (2011). Examining drivers of online purchase intensity : Moderating role of adoption duration insustaining post-adoption online shopping. Journal of Retailing and Consumer Services 18, $101-109$.

Pai, F.Y., \& Huang, K.I. (2011). Applying the technology acceptance model to the introduction of healthcare information systems. Technological Forecasting \& Social Change 78, 650-660.

Pontiggiaa, A., \& Virili, F. (2010). Network effects in technology acceptance: Laboratory experimental evidence. International Journal of Information Management, 30, 68-77.

Soroa - Koury, S., \& Yang, K.C.C. (2010).Factors affecting consumers' responses to mobile advertising from a social norm theoretical perspective. Telematics and Informatics, 27, 103-113.

Teo, T. (2011). Factors influencing teachers' intention to use technology: Model development and test, Computers \& Education, 1 -35

Venkatesh, V., \& Davis, F.D. ( 2000). A theoretical extension of the technology acceptance model: Four longitudinal field studies. Management Science, 46(2), 186-204.

Venkatesh,V., Morris, M.G., Davis, G. B., \& Davis, F. D. (2003). User acceptance of information technology: Toward a unified view. MIS Quarterly, 27(3), 425-478.

Yua, P., Li, H.C., \& Gagnon, M.P. (2009). Health IT acceptance factors in long-term care facilities: A cross-sectional survey. International Journal of Medical Informatics, 78, 219-229.

Zhou, T., Lu, Y., \& Wang, B. (2010). Integrating TTF and UTAUT to explain mobile banking user adoption. Journal of Computers in Human Behavior, 26,760 - 767. 